\title{
External Shunt Complications in a Series of 100 Cases
}

\section{Mohameth Faye, Mualaba Celebre*, Yakhya Cissé, Alioune Badara Thiam, Momar Codé Ba and Seydou Boubacar Badiane}

Neurosurgery Department, Fann University Hospital, Dakar, Senegal

*Corresponding Author: Mualaba Celebre, Neurosurgery Department, Fann

University Hospital, Dakar, Senegal.
Received: September 16, 2020

Published: January 01, 2021

(C) All rights are reserved by Mouhameth

Faye., et al.

\begin{abstract}
Introduction: The external ventricular shunt is an emergency procedure allowing the evacuation of cerebrospinal fluid to the outside by placing a ventricular catheter connected to an external drainage bag. There are several factors which may be responsible for the occurrence of complications. The aim of our study was to collect all the external ventricular shunts performed in neurosurgery, to work on their different complications and to establish a comparison with the data in the literature.

Materials and Methods: This was a descriptive study using a retrospective approach about a period of 8 years, from January 2010 to December 2018, on the files of patients who had received an EVS during their hospitalisation at the neurosurgery clinic of the Fann hospital in Dakar.

Results: During our study period 100 patients benefited External Ventricular Shunts that represented 8.8\% frequency of EVS with an average age of 30.19 years, a male predominance, a sex ratio M/F of 1.12 . Thirty EVS were complicated, i.e. $30 \%$, and mechanical complications represented $50 \%$ of the complications compared with $40 \%$ of those that were infectious. The management of infectious complications with biologic antibiotic therapy was the effective means and the average duration of treatment was 18 days. The post-therapy evolution had found a cure in $47 \%$ and the death rate in $53 \%$.

Conclusion: The frequency of complications related to EVS has shown us that they are not part of negligible surgical procedures, which can be placed in any condition and left unattended. It is important that this procedure be performed in an aseptic technical platform environment, by a well experienced surgeon and for a short period of time, while insisting on close monitoring and reduction of time in place.
\end{abstract}

Keywords: External Ventricular Shunt; Complications; Neurosurgery; Dakar

\section{Abbreviations}

EVS: External Ventricular Shunt; IDSA: Infectious Diseases Society of America

\section{Introduction}

The external ventricular shunt is an emergency procedure allowing the evacuation of cerebrospinal fluid to the outside. It consists of putting a ventricular catheter connected to an external drainage bag. This delicate procedure requiring total asepsis is often subject to several complications that the operator can prevent. His effectiveness is tempered by the high risk of complications associated with this method, which is an essential part of patient management. Studies carried out since the existence of the technique show that EVS infection, particularly meningitis, is the main complication, with incidences ranging from $2 \%$ to $22 \%$ and an average of $10 \%$ $[1,2]$. 
Some of them identify several risk factors and thus issue preventive measures and recommendations aimed at reducing the incidence of these complications.

We report our experience, in order to collect all the external ventricular leads performed in neurosurgery, addressing their various complications and making a comparison with the data in the literature.

\section{Materials and Methods}

This was a descriptive study using a retrospective approach about a period of 8 years, from January 2010 to December 2018, on the files of patients who had received an EVS during their hospitalisation at the neurosurgery clinic of the Fann hospital in Dakar.

In fact, we have included all the records of patients who received an EVS during their hospitalisation and whose follow-up was marked by the occurrence of complications.

Patients who have benefited from a diversion other than EVS are not included in this study.

In total, we selected 100 files. The data analysed were: frequency, age, sex, clinical manifestations, imaging, type of hydrocephalus, etiology of hydrocephalus, time to apply the EVS , operator experience, duration of EVS maintenance, clinical picture announcing the complication, type of complication, management of complications and evolution.

The data collected was analysed using SPSS version 24.0 software.

\section{Results}

During our study period patients received various shunts in our department including 500 ventriculoperitoneal shunts, 535 ventriculocisternostomy and 100 external ventricular shunts. Thus, the frequency of EVS was 8.8\%. The average age was 30.19 years with extremes from 1 month to 85 years. The age group most affected was that over 15 years old, with a frequency of $56 \%$, as shown in figure 1. A male predominance was found, with an $\mathrm{M} / \mathrm{F}$ sex ratio of 1.12 .

The clinical state that motivated the EVS was dominated by altered consciousness in 52 cases or $52 \%$, followed by intracranial hypertension syndrome in 36 cases as summarised in table 1.

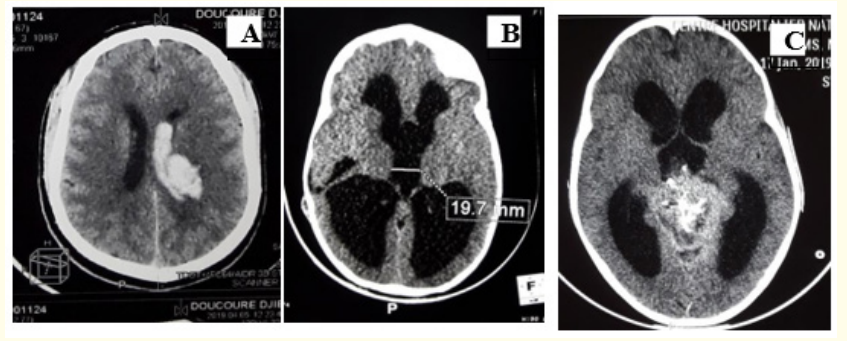

Figure 1: Cerebral CT scan A: Hydrocephalus by subarachnoid haemorrhage with ventricular flooding; B: Post-meningeal tetraventricular hydrocephalus; C: Tri-ventricular hydrocephalus of tumour origin.

\begin{tabular}{|l|c|c|}
\hline Clinical signs & Number & Percentage \\
\hline Altered consciousness & 52 & 52 \\
\hline ICH Syndrome & 36 & 36 \\
\hline Meningeal syndrome & 12 & 12 \\
\hline Total & 100 & 100 \\
\hline
\end{tabular}

Table 1: Clinical events.

ICH: Intracranial Hypertension.

Imaging was dominated by Brain CT in 84\% Off-line Brain MRI 16. The VED was posed in $44 \%$ for tetra ventricular hydrocephalus and hydrocephalus due to sub arachnoid haemorrhage was predominant in $37 \%$ as summarised in table 2 .

\begin{tabular}{|l|c|c|}
\hline Etiologies & Number & Percentage \\
\hline SAH & 37 & 37 \\
\hline Congenital & 16 & 16 \\
\hline Tumours & 26 & 26 \\
\hline Post infectious & 19 & 19 \\
\hline Head trauma & 1 & 1 \\
\hline Ischemia & 1 & 1 \\
\hline Total & 100 & 100 \\
\hline
\end{tabular}

Table 2: Etiologies of hydrocephalus.

SAH: Subarachnoid Hemorrhage.

The average time to maintain the EVS was $4.33 \pm 8.17$ days, with extremes of 1 - 42 days.

Thirty EVS were complicated either 30\% with a predominance of mechanical complications or 15 cases as shown in table 3. 


\begin{tabular}{|l|c|c|}
\hline Complications & Number & Percentage \\
\hline Mechanics & 15 & 50 \\
\hline Infectious & 12 & 40 \\
\hline Hyper drainage & 3 & 10 \\
\hline Total & 30 & 100 \\
\hline
\end{tabular}

Table 3: Complications of an EVS.

Mechanical complications representing 50\% predominated.

Intracranial hypertension in $100 \%$ was the inaugural picture of the mechanical complication. Obstruction was the most predominant mechanical complication in $73 \%$ or 11 cases and dysfunction in only $27 \%$ or 4 cases.

Infectious complications accounted for $40 \%$ of the complications. The predictive clinical picture was dominated by an alteration in general condition in $66.7 \%$ and a meningeal syndrome in $33.3 \%$. Biology found gram positive meningitis in $58.4 \%$ and gram negative meningitis in $41.6 \%$ as summarised in table 4 .

\begin{tabular}{|l|c|c|}
\hline Germs & Numbers & Percentage \\
\hline Gram positive & 7 & 58,3 \\
\hline Streptococcus not groupable & 1 & 8,3 \\
\hline $\begin{array}{l}\text { Staphylocoque aureus methicillin } \\
\text { sensible }\end{array}$ & 6 & 50 \\
\hline Gram negative & 5 & 41,6 \\
\hline Acinetobacter spp & 1 & 8,3 \\
\hline Klebsiella pneumoniae sensible & 2 & 16,6 \\
\hline Klebsiella pneumoniae RC3G & 1 & 8,3 \\
\hline Pseudomona aeruginosa & 1 & 8,3 \\
\hline Total & 12 & 100 \\
\hline
\end{tabular}

Table 4: Germs responsible for infectious complications.

Out of the total number of infected EVS 7 or $58.33 \%$ were carried out by a junior resident, for an average duration of $33.50 \mathrm{~min}$ utes in the 20 to 50 minute extremes and the average duration of VED EVS maintenance was $23.10 \pm 17.59$ days in the 10 to 60 day extremes. EVS due to subarachnoid haemorrhage were the most infected, $58.34 \%$.

The management of complications revealed that all patients with EVS who had complicated an infection were treated with a combination of antibiotics including a $3^{\text {rd }}$ generation cephalosporin (ceftriaxone $100 \mathrm{mg} / \mathrm{kg} /$ day) and either an aminoside (genta- mycin 3 - $5 \mathrm{mg} / \mathrm{kg} /$ day or amikacin $15 \mathrm{mg} / \mathrm{kg} /$ day); except in two cases, one of meningitis with Klebsiella pneumoniae resistant to C3G and the other with multi-resistant Pseudomonas aeruginosa which required the use of imipenem at a dose of $40 \mathrm{mg} / \mathrm{kg} /$ day. The average duration of treatment was 18 days.

As for mechanical complications, management was dominated in $52 \%$ by revision and revision of the EVS in $33.3 \%$ and in $14.8 \%$ by ablation for decompressive craniotomy.

The post-therapy evolution was marked by the declaration of a cure in $47 \%$ for infectious complications with a death rate in $20 \%$. Mechanical complications evolved in 73\% towards death.

\section{Discussion}

Complications related to external ventricular leads are still poorly documented in the literature review. However, some authors $[1,3,4]$ report that infectious complications are the most common. Our study reports $30 \%$ of complications, of which $50 \%$ are mechanical, $40 \%$ infectious and $10 \%$ due to hyper drainage. Without comparing ourselves with other authors who had addressed the issue of complications of external ventricular shunts, we have chosen a summery period at 8 years to have the maximum number of cases.

As known first, mechanical complications in contrast to infectious ones are not documented in the journal in the case of EVS, although several studies only mention them in the case of Ventriculoperitoneal Derivations. Our series found 50\% of mechanical complications linked to shunt dysfunction, with incorrect placement of the ventricular catheter requiring the use of an endoscope for some authors $[5,6]$. Shunt obstruction is the mechanical complication also found, as reported [5,6]. This obstruction is sometimes due to the actions of neurosurgeons during valve placement, which leads some authors, such as [5], to recommend dropping a few drops of LCS once the intra-ventricular catheter is in place in order to eliminate blood and tissue debris capable of inducing an obstruction. This obstruction is located more at the tip of the central catheter of the valve. The clinical manifestations of mechanical complications are dominated by a reappearance of signs of intracranial hypertension with a different symptomatology from one age to another.

Infectious complications are the most frequently reported complications in EVS, as shown [1,3,4]. Our series includes $40 \%$ more infectious complications than those found by some authors. Ac- 
cording to the literature, there is a relationship between the occurrence of these complications and age, as reported [8], which has identified more complications in children, due to the association between causal factors and the immaturity of the immune system, something not found in our series.

Biology had reported meningitis in $100 \%$, of which the germs found were gram-positive in $58.3 \%$, with results almost similar to those found by Luxembourg [9], which had 68.4\% gram-positive meningitis. This means that meningitis on EVS is predominantly gram-positive with staphylococcus as the most common germ found.

The operator's expertise plays an important role in the performance of a surgical procedure. A brain exposed for a long time to the external environment is likely to become infected, because the longer the procedure is carried out, the greater the risk of infection.

Thus, in our series we found that most of the infected valves, $58.34 \%$, were placed by junior neurosurgery residents. The average duration of infected procedures was 33.5 minutes with extremes of 20 to 50 minutes. The literature $[4,10]$ reports that the length of time in place for an EVS plays an important role in the occurrence of possible complications. It estimates the duration of a EVS in place at 10 days and recommends that it be changed if signs for which it was placed persist. However, in our series, the average duration of a EVS was 23 days, which would explain the occurrence of infectious complications related to EVS The etiology of hydrocephalus for which a EVS has been placed also appears to play an important role in the occurrence of infectious complications, as reported by Hoefnagel and Mahé $[11,12]$ who respectively found that the complications found were due to hydrocephalus from sub arachnoid and tumour sub arachnoid haemorrhage for one and intra parenchymal and sub arachnoid haemorrhage for the other, almost similar to our findings where hydrocephalus due to sub arachnoid and tumour sub haemorrhage.

The bi antibiotic therapy with third generation cephalosporins and aminoside has in our given series good results. However, the 2004 IDSA recommendations recommend third generation cephalosporin antibiotics and vancomycin for the treatment of meningitis on EVS.

If the infection persists, intrathecal (intra ventricular) injection of antibiotics seems to play an important role, as advised [10] a dual therapy of gentamycin and vancomycin, which proved ineffective in our series.
In any case changing the infected EVS material and replacing it with a new one would be a factor that would increase the effectiveness of the antibiotic treatment as reported [8], which was not done in our series due to financial limitations.

Hyper drainage is one of the rare complications reported in cases of EVS often presenting signs similar to those of intracranial hypertension, it represented in our series the $10 \%$ of complications of EVS. Brain imaging reports the sign of slit ventricular syndrome [10] requiring ablation of the EVS with as reported [11].

\section{Conclusion}

Our study shows that EVS is a common procedure in neurosurgery, which tends to be left to the inexperienced neurosurgeon, which increases the number of complications. Hence a quid is still outstanding, should it be left to senior surgeons alone?

Thus, the interest of performing this act in an environment with an aseptic technical platform for a short period of time while insisting on close monitoring of this shunt and reducing the time in place. Because both mechanical and infectious complications are avoidable.

\section{Bibliography}

1. Lozier AP., et al. "Ventriculostomy-related infections: a critical review of the literature". Neurosurgery 51.1 (2002): 170-181.

2. Sundgarg G., et al. "Complication due to Prolonged Ventricular fluid Pressure Recording". British Journal of Neurosurgery 2 (1988): 485-495.

3. Lankiang JD. "The external ventricular shunt after cerebromeningeal hemorrhage: indications, results. Retrospective study on 30 patients in the neurosurgery department of the CHNU DE Fann". Med thesis Ucad (2015): 127.

4. Smielewski P., et al. "Evaluation of the transient hyperemic response to test in head injured patients". Journal of Neurosurgery 86 (1997): 773-778.

5. Browd SR., et al. "Failure of cerebrospinal fluid shunts: part I: obstruction and mechanical failure". Pediatric Neurology 34 (2006): 83-92.

6. Rosner MJ. "Cyclic CSF pressure waves causally relate to systemic arterial blood pressure". In: Avezaat CJ, Eijndhoven JH, Mass AI, Tans editions. ICP VIII. Berlin: Spinger-verlag (1991): 414-417. 
7. Holloway KL., et al. "Ventriculostomy infections: the effect of monitoring duration and catheter exchange in 584 patients". Journal of Neurosurgery 85.3 (1991): 419-424.

8. Tunkel AR., et al. "Pratice guidelines for the management of bacterial meningitis". Clinical Infectious Diseases 39.9 (2004): 1267-1284.

9. Yoshihara M., et al. "Cerebrovascular carbon dioxide reactivity assessed by intracranial pressure dynamics in severely head injured patients". Journal of Neurosurgery 82 (1995): 386-393.

10. Bradley EW and Dale M. "Swift complications of ventricular shunt techniques in Neurosurgery 7.3 (2001): 224-242.

11. Rebuck JA., et al. "Infection related to intracranial pressure monitors in adults: analysis of risk factors and antibiotic prophylaxis". Journal of Neurology, Neurosurgery, and Psychiatry 69.3 (2000): 3816-3814.

12. Luxembourger P. "Infection on external ventricular shunt in resuscitation, retrospective mono-centricular study over 4 years". Med thesis, university of Lorraine (2015): 44.

\section{Assets from publication with us}

- Prompt Acknowledgement after receiving the article

- Thorough Double blinded peer review

- Rapid Publication

- Issue of Publication Certificate

- High visibility of your Published work

Website: www.actascientific.com/

Submit Article: www.actascientific.com/submission.php

Email us: editor@actascientific.com

Contact us: +919182824667 